\title{
Age Stage Two-Sex Life Table Reveals Sublethal Effects of Some Herbal and Chemical Insecticides on Adults of Bemisia tabaci (Hem.: Aleyrodidae)
}

\author{
Fatemeh Jafarbeigi, ${ }^{1}$ Mohammad Amin Samih, ${ }^{1}$ Mehdi Zarabi, $^{2}$ and Saeideh Esmaeily ${ }^{1}$ \\ ${ }^{1}$ Department of Plant Protection, Faculty of Agriculture, Vali-e-Asr University, P.O. Box 518, Rafsanjan, Iran \\ ${ }^{2}$ Department of Life Sciences Engineering, Faculty of New Sciences \& Technologies, University of Tehran, P.O. Box 14174, Tehran, Iran \\ Correspondence should be addressed to Fatemeh Jafarbeigi; fatemeh.jafarbeigi@yahoo.com
}

Received 6 January 2014; Revised 6 March 2014; Accepted 11 March 2014; Published 27 April 2014

Academic Editor: Taya Chermenskaya

Copyright (C) 2014 Fatemeh Jafarbeigi et al. This is an open access article distributed under the Creative Commons Attribution License, which permits unrestricted use, distribution, and reproduction in any medium, provided the original work is properly cited.

\begin{abstract}
The sweetpotato whitefly, Bemisia tabaci (Genn.) (Hem.: Aleyrodidae), is an important pest of agriculture in subtropical and tropical areas. In this study, we used the age-stage two-sex life table to evaluate the sublethal effects of the herbal extracts taken from Fumaria parviflora Lam. (Fumariaceae), Teucrium polium L. (Lamiaceae), Calotropis procera (Willd.) R. Br. (Asclepiadaceae), and Thymus vulgaris L. (Lamiaceae) as well as the two commercial synthetic insecticides, pymetrozin and neemarin. The whiteflies were exposed to each insecticide using leaf-dip method. Analysis of life table parameters revealed significant differences $(P \leq 0.05)$ in the net reproductive rate $\left(R_{0}, N R R\right)$, intrinsic rate of increase $\left(r_{m}\right)$, and finite rate of increase $(\lambda)$ among different insecticides. The lowest values of the three population parameters, $R_{0}, r$, and $\lambda$, were observed on whiteflies treated with pymetrozin $(2.455,0.036$, and 1.036), T. polium (2.828, 0.044, and 1.045), and neemarin $(2.998,0.046$, and 1.047), respectively. Results of this study highlights the satisfactory insecticidal effects of the extract taken from T. polium on B. tabaci, which is comparable to the two commonly used synthetic insecticides.
\end{abstract}

\section{Introduction}

The sweetpotato whitefly, Bemisia tabaci (Genn.) (Hem.: Aleyrodidae) is one of the most important pests of agriculture in subtropical and tropical regions as well as in greenhouse production systems across the world [1-4]. Both adult and nymphal stages cause economic damages through a combination of direct feeding on sap phloem [5], excretion of honeydew, which serves as a substrate for growth of black sooty molds [6], and transmission of a large number of plant pathogenic viruses [7-10]. The use of chemical insecticides has long been considered as the primary strategy for control of $B$. tabaci $[10,11]$. However, the rapid and frequent development of resistance against these compounds as well as the unwanted effects of synthetic pesticides on nontarget organisms and environment makes them a nonsatisfactory tool in integrated management programs of B. tabaci. For several decades, the plant-derived insecticides (botanicals) have been considered as potential alternatives to synthetic pesticides due to their safety to human health as well as their low detrimental effects on nontarget organisms and environment.

Plants produce a variety of chemicals that are predominantly used to defend themselves against herbivores [12]. Although, a large number of these substances have been already extracted and identified in different plant species, the availability of botanical insecticides has been limited to a few products [13]. Although, in the immediate future biopesticides may continue to be limited mainly to niche and specialty markets, there is great potential for longterm development and application in different areas of pest management science $[14,15]$. A large volume of studies have been conducted to evaluate the insecticidal properties of plant-derived substances on some important pests [16-23]. 
Traditionally, measurement of the acute toxicity of pesticides to beneficial arthropods has relied largely on the determination of an acute median lethal dose or concentration. However, the estimated lethal dose during acute toxicity tests may only be a partial measure of the deleterious effects. In addition to direct mortality induced by pesticides, their sublethal effects on arthropod physiology and behavior must be considered for a complete analysis of their impact $[24,25]$. Therefore, accurate assessment of sublethal effects is crucial to acquire knowledge on the overall insecticide efficacy in controlling insect pest populations, as well as on their selectivity towards nontarget organisms [26]. On the other hand, it has been shown that the efficacy of insecticide may be different in relation to the times they are used $[27,28]$. Therefore, awareness of pest life tables and plant phenology are very important as the two consequential aspects in pest ecology. Because pest susceptibility to control agents alters between life stages, knowledge on the stage structure of a pest population is necessary for establishing the most effective pesticide application schedule [28]. Since, simulations based on the age-stage, two-sex life table explain the stage structure of a pest population at each time period, the population simulations according to this method can be efficiently used to select the best control strategy based on the stage structure [28]. In this research, we used the age-stage two-sex life table model to analyze the life table parameters of B. tabaci, as a new method to evaluate the sublethal effects of some botanical and synthetic insecticides. They include the extracts taken from Fumaria parviflora, Teucrium polium, Calotropis procera, and Thymus Vulgaris as well as the two commercially available synthetic pesticides, pymetrozin and neemarin.

\section{Materials and Methods}

2.1. Host Plants. We used cotton plants, Gossypium hirsutum var. Varamin, as the main host for mass rearing of B. tabaci and tomato plants, Lycopersicum esculentum var. Bakker brothers, as host in experiments. The cotton and tomato seeds were cultured in transplant trays at greenhouse conditions. Some stand plants were separately transferred in plastic pots $(15 \times 15 \times 20 \mathrm{~cm})$ which filled with a commercial Sterile Plant Growth Media, BAGA (Bastare Amade Giah Arganic, manufactured by Dashte Sabz Atie Co., UTSTP, Iran), while others were planted in hydroponic pots. All pots were kept in $60 \times 50 \times 80 \mathrm{~cm}$ cages covered by fine cloth mesh. Old pots were replaced with new one monthly.

2.2. Study Insects. Adult B. tabaci, collected from native colonies of Rafsanjan cotton fields (Kerman province, South east of Iran), was released on cotton plants in greenhouse of College of Agriculture (Vali-e-Asr University of Rafsanjan). The pupae were analyzed taxonomically and biotype A specimens were isolated and reared as original experimental source. The stock colony was reared in controlled conditions $\left(27 \pm 2^{\circ} \mathrm{C}, 50 \pm 5 \mathrm{RH}\right.$ and $\left.16: 8 \mathrm{~h} \mathrm{~L}: \mathrm{D}\right)$.
Young fully expanded tomato leaves were put in small plastic pots $(10 \mathrm{~cm}$ diameter, height: $15 \mathrm{~cm})$ containing distilled water. The pots were then covered by similar transparent pots to make a transparent glass cages. Adult whiteflies were released into the cages through a small pore located at the upper pot. In order to produce the same age $24 \mathrm{~h}$ adults, the eye-red pupa was checked daily and new born adults were collected and released into glass cages.

2.3. Pesticides. Commercial formulations of the two commonly used insecticides, pymetrozin (Chess $25 \%$ WP, Singenata Company), and azadirachtin (Neemarin EC1500), were used in this study.

2.4. Plant Extract Preparation. Four medicinal plants including fumitory, F. parviflora (Fumariaceae), germander, T. polium (Lamiaceae), swallowwort, C. procera (Asclepiadaceae), and thyme, Th. Vulgaris (Lamiaceae) were used in this study. Herbal parts of plants (leaves and flowers) were collected from natural habitats in Kerman province, southeastern Iran, during their flowering stages (May and June 2010). Plant materials of F. parviflora, T. polium, and Th. vulgaris were collected from Rafsanjan $\left(30^{\circ} 23^{\prime} 46^{\prime \prime} \mathrm{E}\right.$, $\left.55^{\circ} 56^{\prime} 25^{\prime \prime} \mathrm{N}\right)$, while those of $C$. procera were gathered from Jiroft $\left(28^{\circ} 40^{\prime} 37^{\prime \prime} \mathrm{E}, 57^{\circ} 43^{\prime} 52^{\prime \prime} \mathrm{N}\right)$. The collected plants were identified at species level by Dr. M.A. Vakili at the Plant Taxonomy Department of the Islamic Azad University of Jiroft. Sampling was carried out from an average number of 50 plant stalks and three samples were taken from each individual plant. The plant materials were air dried for 45 days and coarsely powdered using an auto mixer. Twenty grams of dried materials were placed on filter paper and steeped in ethanol $(90 \mathrm{~mL})$ and water $(210 \mathrm{~mL})$ for 12 hours. These extractions were prepared according to the Soxhlet extraction method $[29,30]$. Afterwards, rotation was used to reach an extract amount of one-third.

2.5. Concentration-Mortality Response. The effects of five concentrations of the six used pesticides on $B$. tabaci were assayed using the leaf-dip method. Two-leave tomato plants were dipped in pesticide dilutions for $5 \mathrm{~s}$ [31] and then put separately in glass cages. After drying the treated leaflets, fifteen adult $B$. tabaci were released into each cage. The cages were maintained under aforementioned controlled conditions. A solution of $3 \%$ ethanol/distilled water was used as control. The total numbers of dead adults were counted after $24 \mathrm{~h}$. Adults were considered died when they were not able to move properly as a result of stimulation with a soft brush. This assay was conducted in a completely randomized design with three replicates being considered for each insecticide.

2.6. Sublethal Effects on Life History Traits. Adult whiteflies (24 hours old) were released into glass cages containing tomato stalks and allowed to oviposit for $24 \mathrm{~h}$. After oviposition, adults were removed from the cages. Fifty eggs were randomly controlled every $24 \mathrm{~h}$ and the egg duration was recorded. After that all immature stages (nymph and pupa) growth periods were studied daily. Tomato leaflets were 
dipped in the lethal concentration 25\% (LC25) of each insecticide for $5 \mathrm{~s}$ [31]. After air drying, the plants were transferred to the glass cages. Thirty new emerged adults were randomly captured from the stock colony and released into cages. After $24 \mathrm{~h}$, all adults were removed from the cages and released into new ones. The numbers of eggs laid by each female were recorded by digital microscope Dino Capture and Stereomicroscope and continued until the death of the last female. After adult emergence, the sex ratio of F1 generation was determined based on the method of Gerling [4].

2.7. Data Analysis. Probit analysis was performed to estimate the LC50 and LC25 values using Polo-Plus 2.00 software. The population parameters data were analyzed using SPSS software (version 16). One-way analysis of variance (ANOVA) and Duncan's multiple range tests were conducted to compare the effects of different insecticides on life table parameters of B. tabaci $(P<0.05)$. The life table parameters were analyzed using age-stage two-sex life table and female age-specific life table methods.

In age-stage two-sex life table, developmental time of all individuals, including males, females, and those dying before adult stage, as well as female daily fecundity was analyzed according to the age-stage, two-sex life table [32, 33]. Processing of raw data analysis was facilitated by a computer program; TWOSEX-MSChart [34]. No standard error was calculated for the data which was analyzed by the TWOSEX-MSChart program [34]. Various life table parameters including the age-stage specific survival rate $\left(s_{x j}\right.$, where $x=$ age and $j=$ stage), the age-stage specific life expectancy $\left(e_{x j}\right.$, where $x=$ age and $j=$ stage; it gave the expected time that an individual of age $x$ and stage $j$ will live), the age-stage specific fecundity $\left(f_{x j}\right)$, the mean fecundity $(F)$, which explained the contribution of an individual of age $x$ and stage $j$ to the future population, the age-specific survival rate $\left(l_{x}\right)$, the age-specific fecundity $\left(m_{x}\right)$, and the population parameters $(r$, the intrinsic rate of increase; $\lambda$, the finite rate of increase, $\lambda=e^{r} ; R_{0}$, the net reproductive rate; and $T$, the mean generation time) were calculated according to Chi method [33].

The intrinsic rate of increase was appraised using iterative bisection method from the following equation using age indexed from 0 [35]:

$$
\sum_{x=0}^{\infty} e^{-r(x=1)} l_{x} m_{x}=1
$$

The mean generation time was explained as the time length that a population requires increasing to $R_{0}$-times of its size as the firmly fixed age distribution to obtain the stable increase rate of population. In other words, it means $e^{r T}=R_{0}$ or $\lambda^{T}=R_{0}$. The mean generation time $(T)$ and the gross reproductive rate (GRR) were calculated by equations the following, respectively:

$$
\begin{gathered}
T=\frac{\operatorname{LnR_{0}}}{r}, \\
\mathrm{GRR}=\sum m_{x} .
\end{gathered}
$$

TABLE 1: The $\mathrm{LC}_{25}$ ratio $(\mathrm{mg} / \mathrm{mL})$, slop $\pm \mathrm{SE}$, lower and upper $95 \%$ confidence intervals, and $\chi^{2}$ of some synthetic and botanical insecticides on B. tabaci.

\begin{tabular}{lcccc}
\hline Insecticides & Slop \pm SE & LC $_{25}$ & Limits 95\% & $\chi^{2}$ \\
\hline Pymetrozin & $2.236 \pm 0.357$ & 0.089 & $53.99-120.47$ & 1.936 \\
Neemarin & $1.073 \pm 0.194$ & 0.070 & $0.023-0.129$ & 0.171 \\
Th. vulgaris & $1.991 \pm 0.432$ & 69.087 & $36.78-95.09$ & 4.122 \\
T. polium & $2.011 \pm 0.366$ & 90.948 & $50.76-125.97$ & 0.463 \\
F. parviflora & $2.936 \pm 0.654$ & 314.082 & $183.35-406.95$ & 3.553 \\
C. procera & $2.100 \pm 0.498$ & 250.532 & $130.37-338.92$ & 0.762 \\
\hline
\end{tabular}

Chi [33] demonstrated that the relationship among the mean female fecundity $(F)$ and the net reproductive rate $\left(R_{0}\right)$ can be explained as

$$
R_{0}=F\left(\frac{N_{f}}{N}\right)
$$

where $N$ is the total number of individuals used at the start of the life table study and $N_{f}$ is the number of the emerged female adults from these $N$ eggs. This also means $N_{f} \times F=$ $R_{0} \times N$. On the other hand, the total number of offspring produced by all females is equal to the net reproductive rate multiply the cohort size. This relationship shows the accuracy in the age-stage, two-sex life table analysis [33].

In the age-specific female life table, the data were calculated according to Carey method [36]. Jackknife resampling methods were used to calculate the mean and standard error of population parameters [37].

\section{Results}

3.1. Concentration-Mortality Response. Log-probit regression analyses of concentration-mortality data showed that, $24 \mathrm{~h}$ after exposure of adult $B$. tabaci to the six studied insecticides, the $\mathrm{LC}_{25}$ values for different concentration of pymetrozin $(106,150,210,298,420$, and $593 \mu \mathrm{g} / \mathrm{mL})$, neemarin, $(0.060$, $0.135,0.330,0.780$, and $1.860 \mathrm{mg} / \mathrm{mL})$, Th. vulgaris, $(44,58$, $76,100,132,173$, and $228 \mathrm{mg} / \mathrm{mL})$, T. polium $(58,76,100,132$, $173,223,300$, and $395 \mathrm{mg} / \mathrm{mL})$, F. parviflora $(100,153,234,359$, 550 , and $842 \mathrm{mg} / \mathrm{mL})$, and C. procera $(200,283,400,566$, and $800 \mathrm{mg} / \mathrm{mL}$ ) were 89.95 and $0.070 \mu \mathrm{g} / \mathrm{mL}$ and $69,90.9,314$, and $250.5 \mathrm{mg} / \mathrm{mL}$, respectively (Table 1).

3.2. Sublethal Effects. The age-stage survival rate $\left(S_{x j}\right)$ (Figure 1) shows the probability that a new born pupa will survive to age $x$ and stage $j$. In addition to survival, this curve also illustrates the stages difference, stages overlapping, and the variable developmental rate between individuals $[33,38]$. As the figure shows that all adults emerged on the same day in all treatments, but the females survived longer than the males (Figure 1).

The $l_{x}$ curve shows the probability that a newborn pupa will survive to age $x$. Results showed that the survival duration adult whiteflies (from birth to death) were 36, 36, $35,33,30,33$, and 35 days in control, pymetrozin, neemarin, $T$. polium, C. procera, Th. Vulgaris, and F. parviflora treatments, 

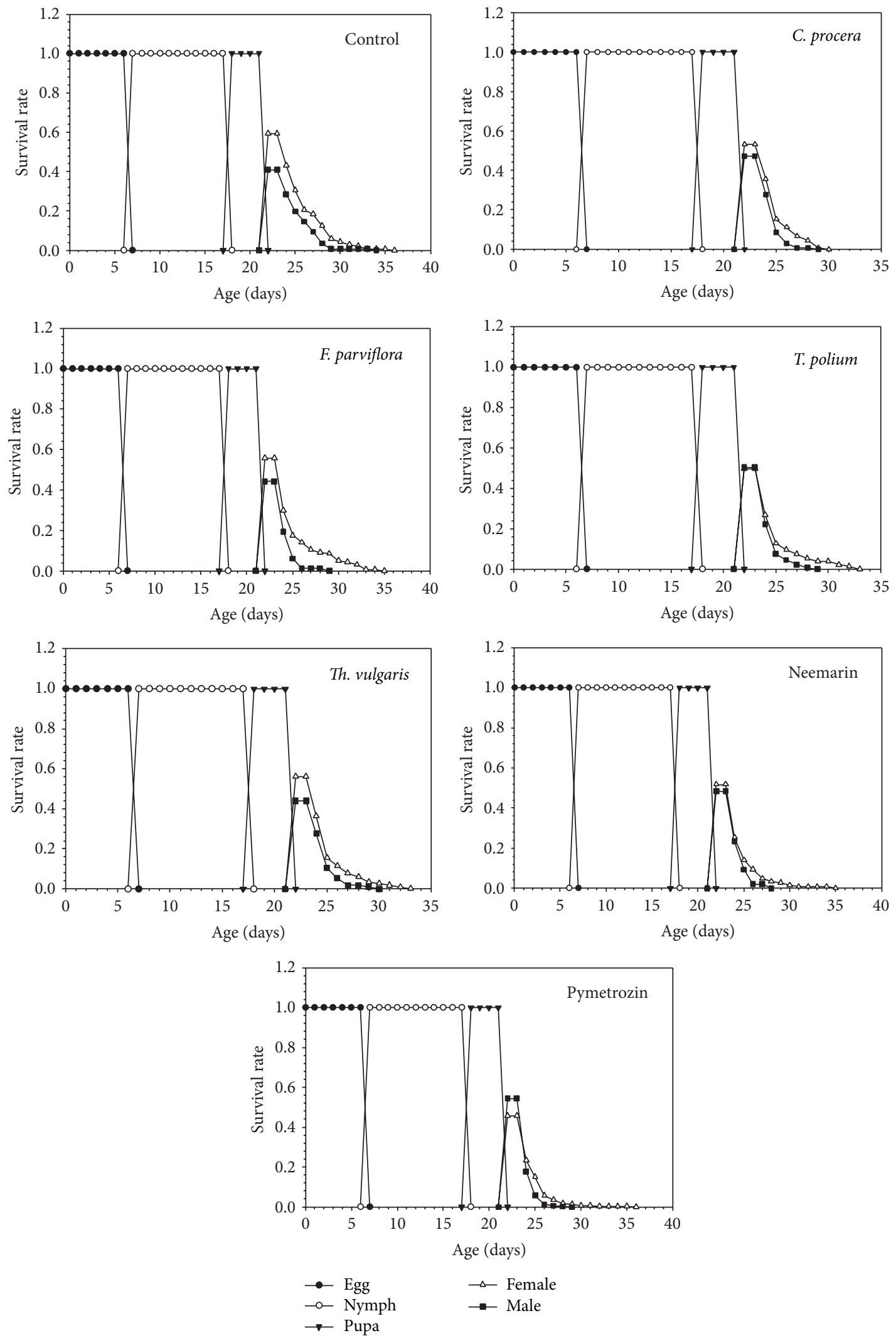

FIGURE 1: Effects of some synthetic and botanical insecticides on age-stage specific survival rate $\left(s_{x j}\right)$ of $B$. tabaci. 
respectively. The highest rate of longevity was observed in control and pymetrozin treatments (36 days), while the lowest longevity was recorded for $C$. procera extract (30 days). Our results also showed that the survival rate of females was 15,15 , $14,12,9,12$, and 14 days for control, pymetrozin, neemarin, $T$. polium, C. procera, Th. Vulgaris, and F. parviflora, respectively.

The life expectancies $\left(e_{x j}\right)$ of adult $B$. tabaci calculated using the life duration of female and male whiteflies after the appearance of newborn adults were 4.40, 3.16, 3.21, 3.46, $3.37,3.52$, and 3.83 days for adult females and 3.94, 2.47, 2.75, $2.73,2.85,3.07$, and 2.65 days for adult males in control, pymetrozin, neemarin, T. polium, C. procera, Th. Vulgaris, and $F$. parviflora treatments, respectively. The lowest life expectancy of adult females was observed in whiteflies treated by pymetrozin, neemarin, and C. procera, respectively.

3.3. Population Parameters. The results of statistical analysis revealed significant differences in sublethal effects of the synthetic and botanical insecticides on the net reproductive rate $(F=8.271 ; \mathrm{df}=6,37 ; P<0.001)$, the intrinsic rate of increase $(F=8.619$; $\mathrm{df}=6,37 ; P<0.001)$, and the finite rate of increase $(F=8.688$; $\mathrm{df}=6,37 ; P<$ $0.001)$. The average values for $R_{0}, \lambda, r$, and $T$ parameters have been shown in Table 2 . The highest and the lowest values of gross reproductive rate were observed in control (39.61) and C. procera (17.16), respectively. The lowest value of net reproductive rate was detected in pymetrozin (2.45), while the whiteflies in control showed the highest net reproductive rate. The highest amount of intrinsic rate of increase and finite rate of increase was observed in the control (0.076 and 1.079, resp.), while the lowest values were recorded for whiteflies treated by pymetrozin ( 0.036 and 1.036 , resp.). The lowest value of mean generation time was recorded in whiteflies treated by pymetrozin (25.28) and C. procera (25.43). while the longest generation time was observed in those treated by T. polium (30.76) (Table 2).

The net reproductive rate $\left(R_{0}\right)$ and the mean female fecundity $(F)$ of control, pymetrozin, neemarin, T. polium, $C$. procera, Th. Vulgaris, and F. parviflora were 7.32, 2.45, 2.99, $2.82,3.18,3.67$, and 4.91 offspring and 14.15, 5.38, 5.97, 5.58, $6.68,6.45$, and $9.07 \mathrm{egg} /$ adults, respectively.

3.4. Comparison of Age-Stage Two-Sex Life Table and the Female Age-Specific Life Table. To make a comparison between the efficiency of two commonly used models, the population parameters of whiteflies treated by all insecticides were simultaneously calculated using both age-specific female life table and age-stage two-sex life table (Table 3). Statistical analyses revealed no significant difference among parameters calculated by these models.

\section{Discussion}

In the present study, we conducted some bioassays to assess the sublethal effects of pymetrozin and neemarin as well as the extracts taken from F. parviflora, T. polium, C. procera, and Th. vulgaris on demographical parameters of B. tabaci. Meanwhile, we compared the age-stage two-sex life table and the female age-specific life table to clarify the differences between the two methods. The life-table studies under different environmental conditions and on different host plants have been proposed to be a relatively time-consuming process; thus the use of life tables in pest management programs seems not to be appropriate. However, the life table studies provide us with some basic knowledge about the biological properties of studied pests, without them development of an appropriate control strategy is impractical [38].

The traditional age-specific life tables [39-41] concentrate only on the survival and the fecundity of the female population, thus ignoring the male population, the stage differences, and stage overlapping leading to a miscalculation in the survival and fecundity curves [33,42]. To overcome these problems, the age-stage two-sex life table has been developed by Chi and Liu [32] and Chi [33]. The age-stage two-sex life table has been widely used to study the population dynamics of insect [38, 43-45]. As far as we know, this study is the first one that uses the life table parameters as a suitable index for evaluation of sublethal effects of insecticides on B. tabaci.

Our results showed that the female whiteflies survived longer than the males and the lowest survival rate of females was observed in T. Polium followed by neemarin. In the usual condition without application of pesticides, female whiteflies have been shown to survive longer than the males [43].

In our study, the overlapping in curves of $S_{x j}$ shows the potential of the age-stage two-sex life table in displaying the stage dissociation of $B$. tabaci due to variable developmental rate between individuals. Similarly, stage differentiation can be perceived in curves of $e_{x j}$. In addition to stage overlapping, a correct relationship between $R_{0}$ and $F$ can be received. In our research, the total number of offspring produced by all females was nearly equal to the net reproductive rate multiplied by the cohort size and the minor difference was attributed to rounding-off. This equality shows the accuracy of the age-stage two-sex life table analysis. These results in all treatments were consistent with the relationship obtained by Chi [33], and Yang and Chi [43].

According to our results, the survival of a population can be predicted at each condition. Our results are in line with those of Chi and Su [42], Yang and Chi [43], and $\mathrm{Hu}$ et al. [38] who showed the variable developmental rate and overlapping among different stages using age-stage twosex life table. Results of our current study clearly showed that the susceptibility to pesticides and botanical compounds varied significantly among different developmental stages of B. tabaci. These findings are in accordance with those results of Liu and Stansly [46] on B. argentifolii.

Yang and Chi [43] proved that $R_{0} \leq F$ meaning that the net reproductive rate is lower than the mean female fecundity. If there was preadult mortality, $R_{0}$ is expected to be lower than $F$, a condition that was shown by our results as well. In contrast to our results, Liu and Stansly [47] reported that the net reproductive rate was higher than the mean fecundity (i.e., $R_{0}>F$ ). This repugnance may be related to the methods they used for calculation of $R_{0}$ and $F$.

The results of comparison between the age-stage two-sex life table and the traditional age specific life table indicated that consideration of male whiteflies in calculation of life table 


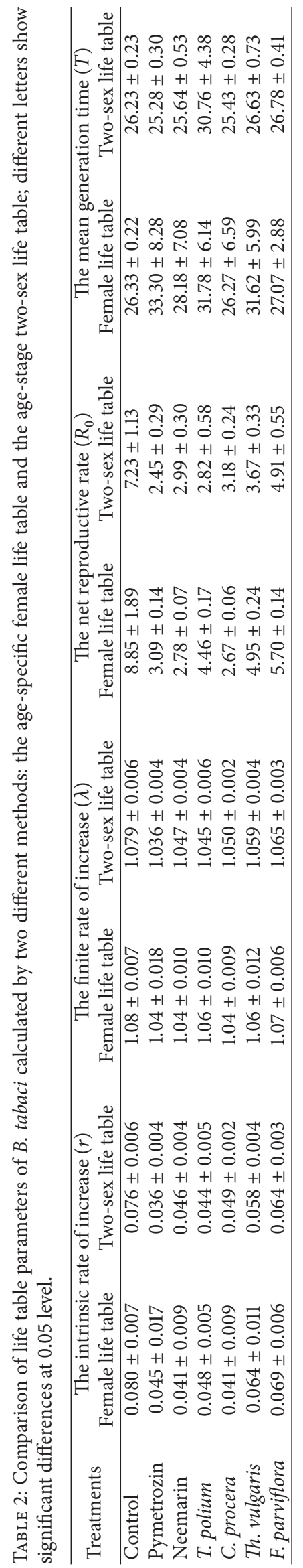


TABLE 3: Results of $t$-test analyses showing differences between the age-specific female life table and the age-stage two-sex life table in estimation of life table parameters of $B$. tabaci.

\begin{tabular}{|c|c|c|c|c|c|c|c|c|}
\hline \multirow[t]{2}{*}{ Treatments } & \multicolumn{2}{|c|}{$\begin{array}{l}\text { The intrinsic rate of increase } \\
\qquad(r)\end{array}$} & \multicolumn{2}{|c|}{$\begin{array}{l}\text { The finite rate of increase } \\
(\lambda)\end{array}$} & \multicolumn{2}{|c|}{$\begin{array}{l}\text { The net reproductive rate } \\
\qquad\left(R_{0}\right)\end{array}$} & \multicolumn{2}{|c|}{$\begin{array}{l}\text { The mean generation time } \\
(T)\end{array}$} \\
\hline & $P$ & $t$ & $P$ & $t$ & $P$ & $t$ & $P$ & $t$ \\
\hline Control & 0.661 & 0.449 & 0.655 & 0.457 & 0.492 & 0.707 & 0.774 & 0.293 \\
\hline Pymetrozin & 0.670 & 0.434 & 0.633 & 0.486 & 0.048 & 2.126 & 0.317 & 1.040 \\
\hline Neemarin & 0.773 & -0.293 & 0.807 & -0.249 & 0.353 & -0.958 & 0.798 & 0.262 \\
\hline T. polium & 0.679 & 0.425 & 0.266 & 1.162 & 0.011 & 3.019 & 0.905 & 0.122 \\
\hline C. procera & 0.556 & -0.602 & 0.590 & -0.550 & 0.016 & -2.700 & 0.919 & 0.103 \\
\hline Th. vulgaris & 0.643 & 0.475 & 0.604 & 0.533 & 0.008 & 3.183 & 0.491 & 0.710 \\
\hline F. parviflora & 0.526 & 0.652 & 0.499 & 0.696 & 0.124 & 1.644 & 0.936 & 0.082 \\
\hline
\end{tabular}

indices and variable developmental rates had little effects on population parameters of $B$. tabaci. The suitability of age stage two-sex life table for calculation of population parameters has been also approved by several previous studies [44].

In recent decades, with the increasing knowledge on detrimental effects of chemical pesticides on human, environment, and nontarget organisms (e.g., development of resistance by key pests, environmental pollution, human health dangers, and pest resurgence), the use of environmentally friendly compounds with the least side effects on nontarget organisms and environment have received relatively great attention. Among these compounds, the plant-derived insecticides have been traditionally considered as efficient candidate alternative to synthetic insecticides [15, 48]. A large numbers of studies have clarified that the extracts taken from the four plant species, T. polium, F. parviflora, Th. Vulgaris, and C. procera, have insecticidal properties [16-22, 49]. Our current study, however, showed that in addition to the direct mortality caused by these compounds they may also impose some sublethal effects on target pests. These effects included decreased growth, fecundity, and survival rate, increased development time, and probably increased susceptibility to natural enemies. In our study, the lowest values of $r_{m}$ were observed in whiteflies treated by pymetrozin, T. polium, and C. procera. Therefore, the two mentioned botanical insecticides seem to be suitable for integrated management programs of B. tabaci. Altogether, results of the current study showed that some biological characteristics of the cotton whiteflies are affected at sublethal concentrations of the studied insecticides. These effects are easily distinguishable using the age stage two-sex life table method used in this study. However, before decision making for establishment of a control strategy using these insecticides, their effects on nontarget organisms, especially natural enemies, should be also evaluated.

\section{Conflict of Interests}

The authors declare that there is no conflict of interests regarding the publication of this paper.

\section{Acknowledgments}

The authors are most grateful to Professor Hsin Chi (Laboratory of Theoretical and Applied Ecology, Department of Entomology, National Chung Hsing University Taichung, Taiwan) for his valuable contributions to this paper. The authors thank Dr. Rouhollah Rahmani for generously helping with editing.

\section{References}

[1] A. H. Greathead, "Host plants," in Bemisia Tabaci a Literature Survey on the Cotton Whitefly with an Annotated Bibliography, M. J. W. Cock, Ed., pp. 17-26, International Institute of Biological Control, Berkshire, UK, 1986.

[2] J. H. Martin, "An identification guide to common whitefly pest species of the world (Homoptera: Aleyrodidae)," in Tropical Pest Management, vol. 33, no. 4, pp. 298-322, 1987.

[3] D. N. Byrne and M. A. Houk, "Morphometric identification of wing polymorphism in Bemisia tabaci (Genn.) (Homoptera: Aleyrodidae)," in Annals of the Entomological Society of America, vol. 83, no. 3, pp. 487-493, 1990.

[4] D. Gerling, Whiteflies: Their Bionomics, Pest Status and Management, Intercept Ltd, Wimborne, UK, 1990.

[5] M. A. Husain and K. N. Trehan, "Final report on the scheme of investigation on the whitefly on cotton in the Punjab," The Indian Journal of Agricultural Sciences, vol. 10, pp. 101-109, 1940.

[6] M. J. Berlinger, "Host plant resistance to Bemisia tabaci", Agriculture, Ecosystems and Environment, vol. 17, no. 1-2, pp. 6982, 1986.

[7] R. C. Dickson, M. Johnson, and E. F. Laird, "Leaf crumples a virus disease of cotton," Phytopathology, vol. 44, pp. 479-480, 1956.

[8] J. E. Duffus, "Whitefly transmission of plant viruses," in Current Topics in Vector Research, K. H. Harris, Ed., vol. 4, pp. 73-91, Springer, New York, NY, USA, 1987.

[9] I. D. Bedford, R. W. Briddon, J. K. Brown, R. C. Rosell, and P. G. Markham, "Geminivirus-transmission and biological characterisation of Bermisia tabaci (Gennadius) biotypes from different geographic regions," Annals of Applied Biology, vol. 125, no. 2, pp. 311-325, 1994.

[10] D. G. Riley and W. Tan, "Host plant effects on resistance to bifenthrin in silverleaf whitefly (Homoptera: Aleyrodidae)," 
Journal of Economic Entomology, vol. 96, no. 4, pp. 1315-1321, 2003.

[11] Y. O. H. Assad, N. H. H. Bashir, and E. M. A. Eltoum, "Evaluation of various insecticides on the cotton whitefly, Bemisia tabaci (Genn.), population control and development of resistance in Sudan Gezira," Resistant Pest Management Newsletter, vol. 15, pp. 7-12, 2006.

[12] W. Dermauwa, N. Wybouwa, S. Rombautsb et al., "A link between host plant adaptation and pesticide resistance in the polyphagous spider mite Tetranychus urticae," Proceedings of the National Academy of Sciences of the United States of America, vol. 110, no. 2, pp. E113-E122, 2012.

[13] M. B. Isman, "Botanical insecticides, deterrents, and repellents in modern agriculture and an increasingly regulated world," Annual Review of Entomology, vol. 51, pp. 45-66, 2006.

[14] L. G. Copping and J. J. Menn, "Biopesticides: a review of their mode of action and efficacy," Pest Management Science, vol. 56, no. 8, pp. 651-676, 2000.

[15] A. Ali, F. Ahmad, A. Biondi, Y. Wang, and N. Desneux, "Potential for using Datura alba leaf extracts against two major stored grain pests, the khapra beetle Trogoderma granarium and the rice weevil Sitophillus oryzae," Journal of Pest Science, vol. 85, no. 3, pp. 359-366, 2012.

[16] L. A. Hummelbrunner and M. B. Isman, "Acute, sublethal, antifeedant, and synergistic effects of monoterpenoid essential oil compounds on the tobacco cutworm, Spodoptera litura (Lep., Noctuidae)," Journal of Agricultural and Food Chemistry, vol. 49, no. 2, pp. 715-720, 2001.

[17] E. H. Koschier and K. A. Sedy, "Labiate essential oils affecting host selection and acceptance of Thrips tabaci lindeman," Crop Protection, vol. 22, no. 7, pp. 929-934, 2003.

[18] A. M. El-Shazly and K. T. Hussein, "Chemical analysis and biological activities of the essential oil of Teucrium leucocladum Boiss. (Lamiaceae)," Biochemical Systematics and Ecology, vol. 32, no. 7, pp. 665-674, 2004.

[19] N. M. Arab, R. Ebadi, B. Hatami, and Kh. J. Talebi, "Insecticidal effects of some plant extracts on Callosobruchus maculatus F. under laboratory condition and Laphigma exigua $\mathrm{H}$. in greenhouse," Journal of Science and Technology of Agriculture and Natural Resources, vol. 11, pp. 221-234, 2008.

[20] M. S. Al-mazra'awi and M. Ateyyat, "Insecticidal and repellent activities of medicinal plant extracts against the sweet potato whitefly, Bemisia tabaci (Hom.: Aleyrodidae) and its parasitoid Eretmocerus mundus (Hym.: Aphelinidae)," Journal of Pest Science, vol. 82, no. 2, pp. 149-154, 2009.

[21] E. Sertkaya, K. Kaya, and S. Soylu, "Chemical compositions and insecticidal activities of the essential oils from several medicinal plants against the cotton whitefly, Bemisia tabaci," Asian Journal of Chemistry, vol. 22, no. 4, pp. 2982-2990, 2010.

[22] A. Taghizadeh-Sarokalaii and S. Moharramipour, "Fumigant toxicity of essenssial oil, Thymus persicus (Lamiaceae) and Prangos acaulis (Apiaceae) on Callosobruchus maculatus (Coleoptera: Bruchidae)," Iranian Journal of Plant Protection Science, vol. 33, pp. 55-68, 2010.

[23] F. Jafarbeigi, M. A. Samih, M. Zarabi, and S. Esmaeily, "Effect of some herbal compounds on biological parameters of Bemisia tabaci (Genn.) (Hem.: Aleyrodidae) on tomato under controlled condition," Journal of Plant Protection Research, vol. 52, no. 4, pp. 375-380, 2012.

[24] N. Desneux, A. Decourtye, and J.-M. Delpuech, "The sublethal effects of pesticideson beneficial arthropods," Annual Review of Entomology, vol. 52, pp. 81-106, 2007.
[25] N. Desneux, X. Fauvergue, F.-X. Dechaume-Moncharmont, L. Kerhoas, Y. Ballanger, and L. Kaiser, "Diaeretiella rapae limits Myzus persicae populations after applications of deltamethrin in oilseed rape," Journal of Economic Entomology, vol. 98, no. 1, pp. 9-17, 2005.

[26] A. Biondi, N. Desneux, G. Siscaro, and L. Zappalà, "Using organic-certified rather than synthetic pesticides may not be safer for biological control agents: selectivity and side effects of 14 pesticides on the predator Orius laevigatus," Chemosphere, vol. 87, no. 7, pp. 803-812, 2012.

[27] B. H. Stanley, W. H. W. L. Reissig, M. Roelofs, R. Schwarz, and C. A. Shoemaker, "Timing treatments for apple maggot (Diptera: Tephritidae) control using sticky sphere traps baited with synthetic apple volatiles," Journal of Economic Entomology, vol. 80, no. 5, pp. 1057-1063, 1987.

[28] H. Chi, "Timing of control based on the stage structure of pest populations: a simulation approach," Journal of Economic Entomology, vol. 83, no. 4, pp. 1143-1150, 1990.

[29] A. L. Vogel, Text Book of Practical-Organic Chemistry, Longman, Harlow, UK, 1978.

[30] M. J. Pascual-Villalobos and A. Robledo, "Screening for antiinsect activity in Mediterranean plants," Industrial Crops and Products, vol. 8, no. 3, pp. 183-194, 1998.

[31] A. Heydari, S. Moharrami pour, A. A. pour mirza, and A. A. Talebi, "Effects of buprofezin, pymetrozin and fenpropathrin on reproductive parameters of Trialeurodes vaporariorum Westwood (Hom: Aleyrodidae)," Applied Entomology and Phytopathology, vol. 71, pp. 29-46, 2003.

[32] H. Chi and H. Liu, "Two new method for the study of insect population ecology," Bulletin of the Institute of Zoology, Academia Sinica, vol. 24, pp. 225-240, 1985.

[33] H. Chi, "Life-table analysis incorporating both sexes and variable development rates among individuals," Environmental Entomology, vol. 17, no. 1, pp. 26-34, 1988.

[34] H. Chi, "TWOSEX-MSChart: a computer program for the age-stage, two-sex life table analysis," 2010, http://140.120 $.197 .173 /$ Ecology/.

[35] D. Goodman, "Optimal life histories, optimal notation and the value of reproductive value," American Naturalist, vol. 119, no. 6, pp. 803-823, 1982.

[36] J. R. Carey, Applied Demography for Biologists with Special Emphasis on Insects, Oxford University Press, New York, NY, USA, 1993.

[37] A. D. H. N. Maia, A. J. B. Luiz, and C. Campanhola, "Statistical inference on associated fertility life table parameters using jackknife technique: computational aspects," Journal of Economic Entomology, vol. 93, no. 2, pp. 511-518, 2000.

[38] L.-X. Hu, H. Chi, J. Zhang, Q. Zhou, and R.-J. Zhang, "Life-table analysis of the performance of Nilaparvata lugens (Hemiptera: Delphacidae) on two wild rice species," Journal of Economic Entomology, vol. 103, no. 5, pp. 1628-1635, 2010.

[39] E. G. Lewis, "On the generation and growth on the population," Sankhya, vol. 6, pp. 93-96, 1942.

[40] P. H. Leslie, "On the use of matrices in certain population mathematics," Biometrika, vol. 33, no. 3, pp. 183-212, 1945.

[41] L. C. Birch, "The intrinsic rate of natural increase of an insect population," Journal of Animal Ecology, vol. 17, no. 1, pp. 15-26, 1948.

[42] H. Chi and H.-Y. Su, "Age-stage, two-sex life tables of Aphidius gifuensis (Ashmead) (Hymenoptera: Braconidae) and its host 
Myzus persicae (Sulzer) (Homoptera: Aphididae) with mathematical proof of the relationship between female fecundity and the net reproductive rate," Environmental Entomology, vol. 35, no. 1, pp. 10-21, 2006.

[43] T.-C. Yang and H. Chi, "Life tables and development of Bemisia argentifolii (Homoptera: Aleyrodidae) at different temperatures," Journal of Economic Entomology, vol. 99, no. 3, pp. 691698, 2006.

[44] R. Farhadi, H. Allahyari, and H. Chi, "Life table and predation capacity of Hippodamia variegata (Coleoptera: Coccinellidae) feeding on Aphis fabae (Hemiptera: Aphididae)," Biological Control, vol. 59, no. 2, pp. 83-89, 2011.

[45] Y.-B. Huang and H. Chi, "Age-stage, two-sex life tables of Bactrocera cucurbitae (Coquillett) (Diptera: Tephritidae) with a discussion on the problem of applying female age-specific life tables to insect populations," Insect Science, vol. 19, no. 2, pp. 263-273, 2012.

[46] T.-X. Liu and P. A. Stansly, "Toxicity of biorational insecticides to Bemisia argentifolii (Homoptera: Aleyrodidae) on tomato leaves," Journal of Economic Entomology, vol. 88, no. 3, pp. 564568, 1995.

[47] T.-X. Liu and P. A. Stansly, "Life history of Bemisia argentifolii (Homoptera: Aleyrodidae) on Hibiscus rosasinensis (malvaceae)," Florida Entomologist, vol. 81, no. 3, pp. 437-445, 1998.

[48] H. Izadi and M. A. Samih, Biopesticides and Compounds with Novel Mode of Action, Jahad Daneshgahi, Tehran, Iran, 2006.

[49] M. K. Irannejad, The Side-effects of several insecticides and plant extracts on green lacewing Chrysoperla carnea (Neuroptera: Chrysopidae) under laboratory conditions [M.S. thesis], Vali-eAsr University of Rafsanjan, Rafsanjan, Iran, 2010. 

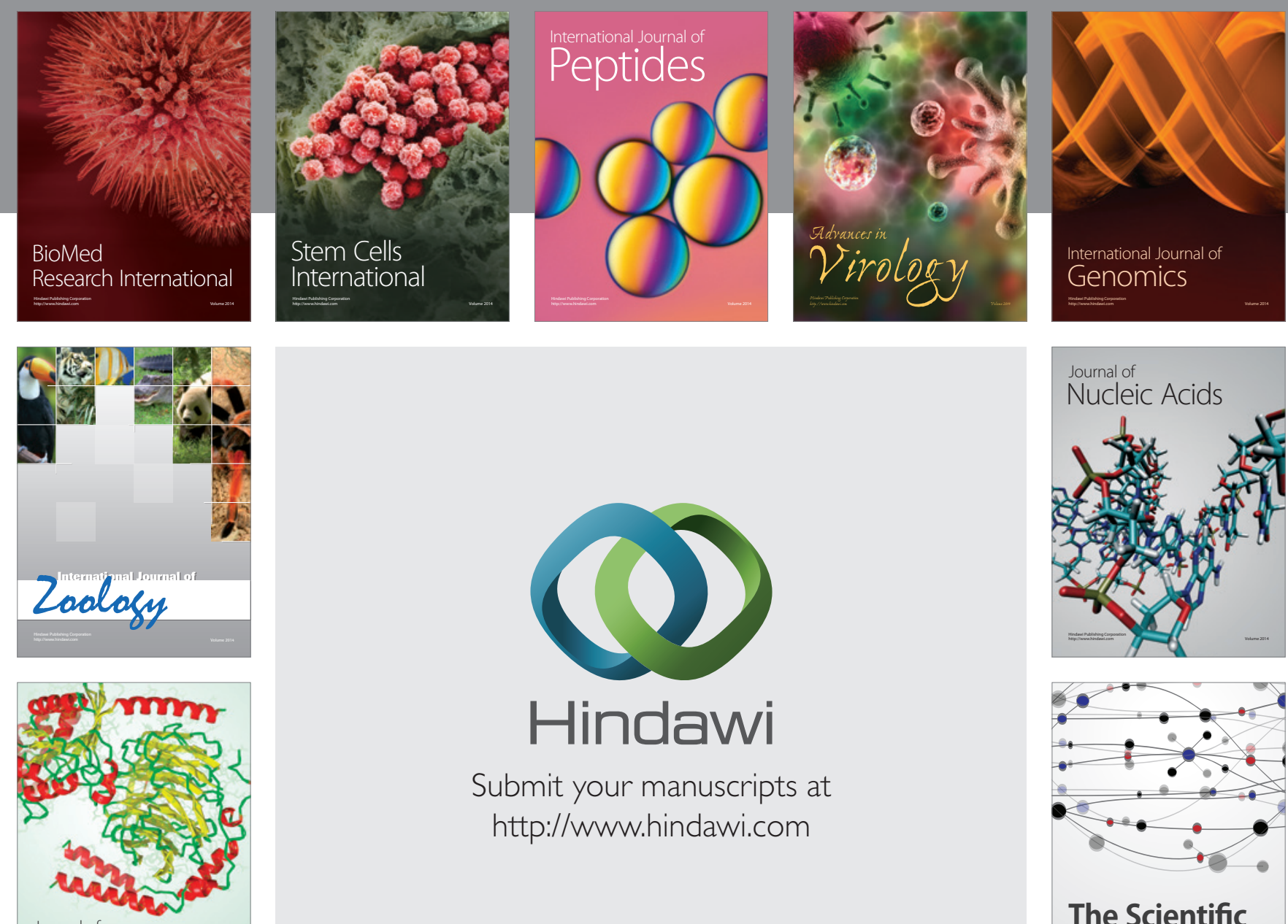

Submit your manuscripts at

http://www.hindawi.com

Journal of
Signal Transduction
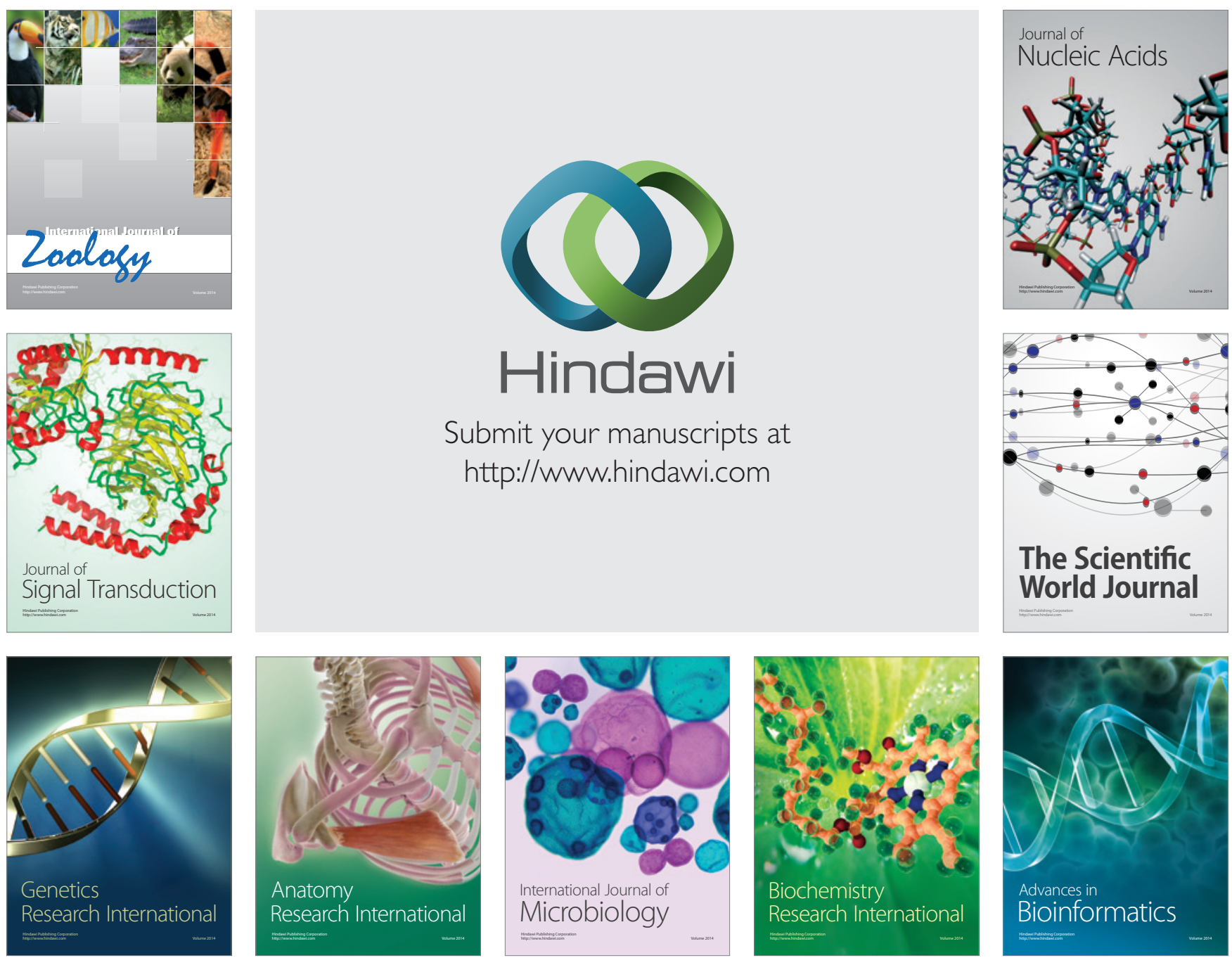

The Scientific World Journal
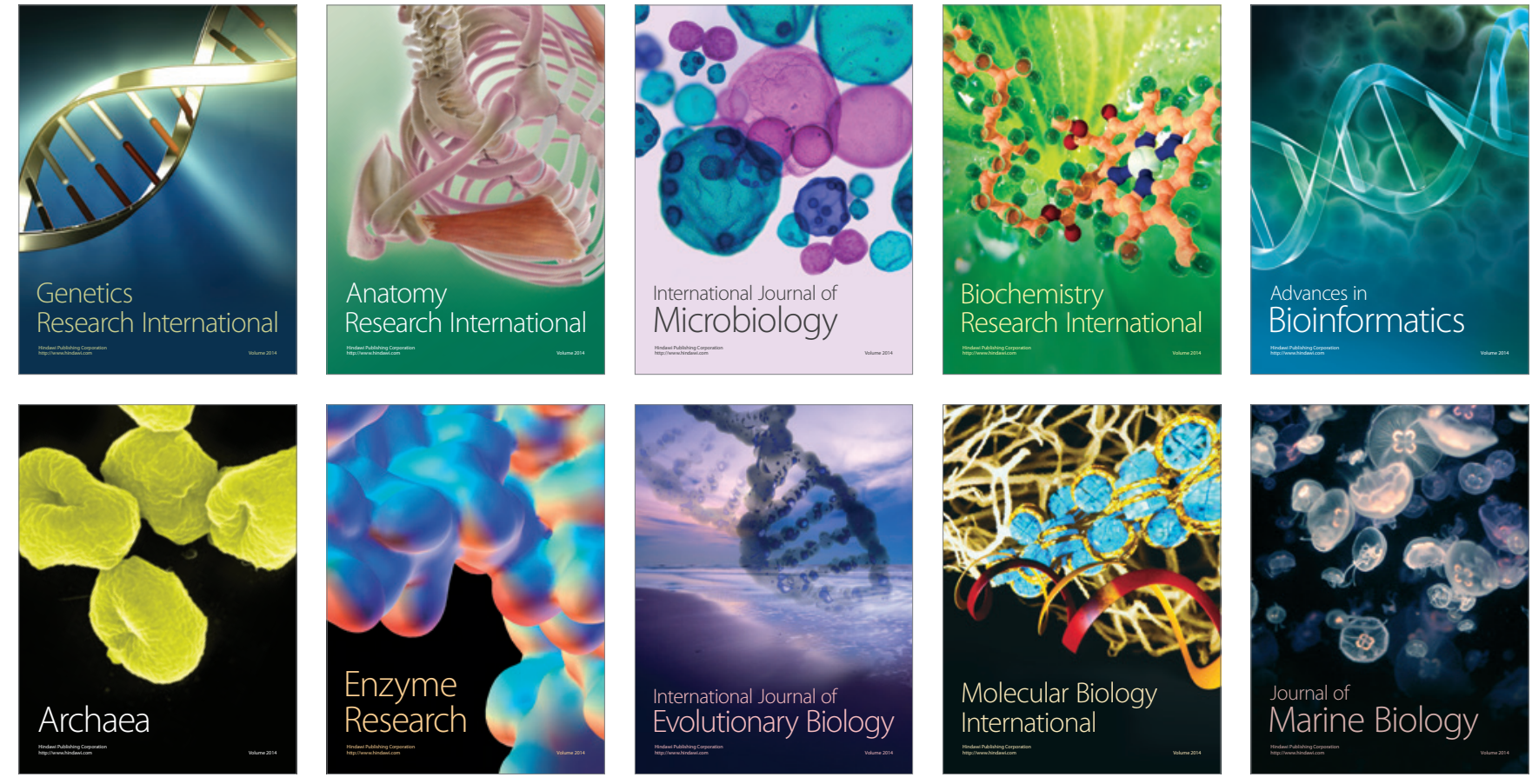